\title{
A New Instrument to Measure Sexual Competence and Interaction Competence in Youth: Psychometric Properties in Female Adolescents
}

Citation for published version (APA):

Grauvogl, A., Peters, M. L., Evers, S. M. A. A., \& van Lankveld, J. J. D. M. (2015). A New Instrument to Measure Sexual Competence and Interaction Competence in Youth: Psychometric Properties in Female Adolescents. Journal of Sex \& Marital Therapy, 41(5), 544-556. https://doi.org/10.1080/0092623x.2014.933461

Document status and date:

Published: 01/01/2015

DOI:

10.1080/0092623x.2014.933461

Document Version:

Publisher's PDF, also known as Version of record

Document license:

Taverne

Please check the document version of this publication:

- A submitted manuscript is the version of the article upon submission and before peer-review. There can be important differences between the submitted version and the official published version of record.

People interested in the research are advised to contact the author for the final version of the publication, or visit the DOI to the publisher's website.

- The final author version and the galley proof are versions of the publication after peer review.

- The final published version features the final layout of the paper including the volume, issue and page numbers.

Link to publication

\footnotetext{
General rights rights.

- You may freely distribute the URL identifying the publication in the public portal. please follow below link for the End User Agreement:

www.umlib.nl/taverne-license

Take down policy

If you believe that this document breaches copyright please contact us at:

repository@maastrichtuniversity.nl

providing details and we will investigate your claim.
}

Copyright and moral rights for the publications made accessible in the public portal are retained by the authors and/or other copyright owners and it is a condition of accessing publications that users recognise and abide by the legal requirements associated with these

- Users may download and print one copy of any publication from the public portal for the purpose of private study or research.

- You may not further distribute the material or use it for any profit-making activity or commercial gain

If the publication is distributed under the terms of Article 25fa of the Dutch Copyright Act, indicated by the "Taverne" license above, 


\section{A New Instrument to Measure Sexual Competence and Interaction Competence in Youth: Psychometric Properties in Female Adolescents}

Andrea Grauvogl, Madelon L. Peters, Silvia M.A.A. Evers \& Jacques J.D.M. van Lankveld

To cite this article: Andrea Grauvogl, Madelon L. Peters, Silvia M.A.A. Evers \& Jacques J.D.M. van Lankveld (2015) A New Instrument to Measure Sexual Competence and Interaction Competence in Youth: Psychometric Properties in Female Adolescents, Journal of Sex \& Marital Therapy, 41:5, 544-556, DOI: 10.1080/0092623X.2014.933461

To link to this article: https://doi.org/10.1080/0092623X.2014.933461

\section{曲 Published online: 04 Sep 2014.}

Submit your article to this journal $\pi$

Llll Article views: 294

Q View related articles $\sqsubset$

View Crossmark data $₫$ 


\title{
A New Instrument to Measure Sexual Competence and Interaction Competence in Youth: Psychometric Properties in Female Adolescents
}

\author{
Andrea Grauvogl and Madelon L. Peters \\ Faculty of Psychology and Neuroscience, Department of Clinical Psychological Science, \\ Maastricht University, Maastricht, The Netherlands \\ Silvia M.A.A. Evers \\ Faculty of Health, Medicine and Life Sciences, Caphri, School of Public Health and Primary \\ Care, Department of Health Services Research, Maastricht University, Maastricht, \\ The Netherlands \\ Jacques J.D.M. van Lankveld \\ Faculty of Psychology, Open University, Heerlen, The Netherlands
}

\begin{abstract}
The Sexual Competence and Interaction Competence in Youth is a self-report questionnaire that aims to measure sexual competence and interaction competence in adolescents. The study sample consisted of 276 female undergraduate students $(M=20.95$ years, $S D=2.00$ years). The factor structure of the questionnaire was calculated on full sample data. A subsample was used to calculate the validity and internal consistency $(N=236 ; M=20.88$ years, $S D=1.96)$. The test-retest reliability was also calculated in a subsample $(N=82 ; M=21.45$ years, $S D=1.74$ years). On the basis of an exploratory factor analysis, 8 factors were extracted: (a) communication about sex, (b) refusing sex, (c) positive sexual attitudes, (d) male role in sexual interaction, (e) contraceptive use, (f) not suppressing problems and desires regarding sex, (g) sexual assertiveness, and (h) sexual hedonism. The subscales possess adequate internal consistency and moderate to excellent test-retest reliability. A higher order principal component analysis revealed a 2-factor structure that appears to adequately represent the sexual competence and interaction competence constructs. Furthermore, convergent and discriminant validity were considered to be good. The results indicate that the Sexual Competence and Interaction Competence in Youth may be a useful instrument to measure sexual and interaction competence among adolescents.
\end{abstract}

Sexuality and romantic and sexual relationships develop during adolescence. Sexual maturation and the development of more complex cognitive functions and skills (e.g., problem solving,

Address correspondence to Andrea Grauvogl, Maastricht University, Faculty of Psychology and Neuroscience, Department of Clinical Psychological Science, P. O. Box 616, 6200 MD Maastricht, The Netherlands. E-mail: andrea.grauvog1@maastrichtuniversity.nl 
decision making; World Health Organization, 2011) increase the likelihood of engaging in a long-term romantic relationship. Being in an enduring relationship during this phase of life allows adolescents to develop the skills necessary to maintain high-quality romantic relationships in later adulthood (Collins, Welsh, \& Furman, 2009). Furthermore, it helps to develop emotional coping skills (i.e. feelings of self-esteem, self-confidence; World Health Organization, 2011) and social or interpersonal skills (i.e. assertiveness, refusal skills, and social competence; World Health Organization, 2011; Zimmerman-Gernbeck, Siebenbruner, \& Collins, 2004). These skills further contribute to healthy sexual development. The World Health Organization (2002) defines sexual health as follows:

... a state of physical, emotional, mental and social wellbeing in relation to sexuality, which is not merely the absence of disease, dysfunction or infirmity. Sexual health requires a positive and respectful approach to sexuality and sexual relationships, as well as the possibility of having pleasurable and safe sexual experiences.

Sexual health problems among adolescents and young adults are very common both in the Western world (Guttmacher Institute, 2010, 2012; Hamilton, Martin, \& Ventura, 2010; Pazol et al., 2011) and in other global regions (World Health Organization, 2002). De Graaf, Kruijer, van Acker, and Meijer (2012) reported that substantial numbers of adolescents in The Netherlands experience sexual dysfunctions (problems with sexual desire, sexual arousal, orgasm, and pain during sexual encounters). Many female adolescents in particular report these problems. Kedde (2012) explored the prevalence of sexual dysfunctions among 608 female adolescents and 459 male adolescents 15 to 24 years of age. Among the female adolescents, $43.4 \%$ experienced at least one sexual dysfunction. Orgasmic disorders were the most frequently reported sexual dysfunction type (20.3\%), followed by lubrication problems (13.8\%), dyspareunia (11.5\%), sexual aversion (8.3\%), vaginismus $(7.9 \%)$, and hypoactive sexual desire disorder $(2.2 \%)$. Among the male adolescents, $27.3 \%$ were found to experience at least one sexual dysfunction. Premature ejaculation was the most frequently reported sexual dysfunction type (12.6\%), followed by erectile disorder (6.4\%), sexual aversion $(5.4 \%)$, orgasmic disorders $(4.5 \%)$, dyspareunia $(2.1 \%)$, and hypoactive sexual desire disorder $(0.6 \%)$.

Sexual competence and interaction competence can be considered as contributors to sexual health. Sexual competence can be described as the ability, based on the pertinent skills and knowledge, to be involved in sexual activities with successful outcomes and in which sexual health is preserved (Hirst, 2008; Wellings et al., 2001). A successful outcome would be a positive sexual experience, one that does not threaten sexual health, as it prevents unwanted pregnancy and transmission of sexually transmitted infections, and avoids the development of sexual dysfunctions, such as pain during intercourse. Furthermore, it means that sexual health is protected in the emotional sense of having enjoyed the encounter, with minimal or no regret afterwards. A successful process concerns the interpersonal process between the individuals participating in a sexual encounter with each respecting the other's sexual health and rights (Hirst, 2008; Wellings et al., 2001). Interaction competence includes expressing desires and boundaries, but also taking the initiative in sexual activities (Bakker \& Vanwesenbeeck, 2006). The description of sexual competence and interaction competence in the literature suggests a strong interconnectedness of both concepts. It is not evident whether both concepts should be considered separately or in combination. 
The role of sexual competence and interaction competence in sexual health of adolescents has received some empirical support. Sexually competent adolescents were found to delay their first sexual intercourse to a later age (Wellings et al., 2001), to have a gradual or progressive sexual development type (from kissing to caressing to caressing without clothes; De Graaf, Meijer, Vanwesenbeeck, \& Poelman, 2005), whereas sexual incompetence was associated with early pregnancy (Wellings et al., 2001), and a jump style or nonlinear sexual development (from kissing almost immediately to sexual intercourse). Interaction competence has been found to be associated with prevention of sexually transmitted infections, HIV/AIDS (Bakker \& Vanwesenbeeck, 2006; Crosby et al., 2002; DiClemente, 1991), pregnancy and emotional well-being (Ferroni \& Taffe, 1997; Widman, Welsh, McNulty, \& Little, 2006), and sexual dysfunctions (Bakker \& Vanwesenbeeck, 2006). These findings indicate that sexual health and sexual functioning are influenced by both sexual competence and interaction competence.

Given the contribution of sexual competence and interaction competence to the development and maintenance of sexual health, an appropriate and psychometrically sound instrument is needed to allow identification of groups in need of help, and to be able to monitor the effect of interventions. Other measures of sexual competence and interaction competence have previously been developed (de Graaf et al., 2005; Snell, 1995; Wellings et al., 2001). Wellings and colleagues (2001) operationalized sexual competence by asking questions about contraceptive use, the main reason for first intercourse, the willingness of the adolescent to engage in sexual encounters, and about the nature of the relationship with their partner. De Graaf and colleagues (2005) operationalized interaction competence by asking questions about expressing sexual feelings, having influence during sexual encounters, taking the initiative in sexual encounters, and about refusing sexual activities. Similarly, Milhausen and colleagues (2007) measured adolescents' frequency of communication with their partner. The Multidimensional Sexual Self-Concept Questionnaire (MSSCQ; Snell, 1995) aims to measure psychological aspects of human sexuality on 20 dimensions.

Although these instruments measure relevant aspects of sexual health, they do not incorporate the full range of elements of sexual competence and interaction competence. Furthermore, with respect to the MSSCQ, the large number of items (100) and the long time needed to complete the questionnaire (45-60 min) might render it less suitable for use in adolescents. Sexual competence and interaction competence have not yet been combined into one single questionnaire. To address the need for a single, short questionnaire for male and female adolescents, we aimed to construct a questionnaire, called the Sexual Competence and Interaction Competence in Youth (SCICY) that measures a combination of sexual competence and interaction competence in youth. In the remainder of this article, we discuss the psychometric properties of this new instrument. Although the SCICY has been developed for both male and female adolescents, this first psychometric analysis has been conducted among female adolescents only. We hypothesized that, with respect to convergent validity, the SCICY total and subscales will have a positive association with the Partner Communication Scale (PCS; Milhausen et al., 2007), a positive correlation with the positive subscales of the MSSCQ (Snell, 1995), and a negative association with the negative subscales of the MSSCQ. With respect to the discriminant validity, we hypothesized that sexually functional adolescents will have higher scores on the SCICY total and subscales than sexually dysfunctional adolescents. 


\section{METHOD}

\section{Participants}

The study sample consisted of 276 female undergraduate students $(M=20.95$ years, $S D=$ 2.00 years). The factor structure of the SCICY was calculated on full sample data. Seventy percent of the participants were in a relationship. A subsample was used to calculate the validity and internal consistency ( $N=236 ; M=20.88$ years, $S D=1.96$ years). Of the participants, $68 \%$ were in a relationship. The test-retest reliability was also calculated in a subsample $(N=82$; $M=21.45$ years, $S D=1.74$ ). Of the participants in the subsample, $66 \%$ were in a relationship.

\section{Measures}

\section{SCICY}

The SCICY is a self-report questionnaire, using 5-point Likert scales, which aims to measure the combination of sexual competence and interaction competence in adolescents. Higher scores indicate higher sexual and interaction competence.

\section{MSSCQ}

The MSSCQ is a 100-item self-report instrument that uses 5-point Likert scales to measure psychological aspects of human sexuality on the dimensions of sexual anxiety, sexual self-efficacy, sexual consciousness, motivation to avoid risky sex, chance/luck sexual control, sexual preoccupation, sexual assertiveness, sexual optimism, sexual problem self-blame, sexual monitoring, sexual motivation, sexual problem management, sexual esteem, sexual satisfaction, power-other sexual control, sexual self-schemata, fear of sex, sexual problem prevention, sexual depression, and internal sexual control. Higher scores indicate a higher position on each dimension. The internal consistency was found adequate (Cronbach's $\alpha=.72$ to .91 ; Snell, 1995).

\section{PCS}

The PCS is a 5-item self-report instrument that uses 4-point Likert scales to measure adolescents' frequency of communicating with a partner about sexual matters. A higher score indicates more frequent sexual communication. The internal consistency (Cronbach's $\alpha=.87$ ) and test-retest reliability $(r=.83)$ were satisfactory (Milhausen et al., 2007).

\section{Female Sexual Function Index}

The Female Sexual Function Index (Rosen et al., 2000) is a 19-item self-report instrument that uses 6-point Likert scales to measure female sexual functioning on the dimensions of sexual desire, arousal, lubrication, orgasm, satisfaction, and pain. A higher total score indicates healthier sexual functioning. The Female Sexual Function Index was translated into Dutch and validated in samples of women with and without sexual dysfunctions in The Netherlands. It has sound psychometric properties (ter Kuile, Brauer, \& Laan, 2006). High internal consistency was demonstrated for all 
subscales in sexually dysfunctional (Cronbach's $\alpha=.82$ to .93 ) and healthy women (Cronbach's $\alpha=.83$ to .95 ; Rosen et al., 2000). The test-retest reliability was satisfactory for all subscales in both groups ( $r=.68$ to .80 and $r=.77$ to .91 , respectively).

\section{Procedure}

The study was evaluated and approved by the Ethics Committee of the Faculty Psychology and Neuroscience of Maastricht University. Participants were recruited using flyers and a Web site for students who wished to apply for research participation. Adolescents interested in participating in the study sent an e-mail to the researchers. The participants were then instructed through e-mail to complete the questionnaires on a secure Web site. To access this website, the participant had to insert a research and participant number and a separately sent password. To conduct the test-retest reliability, we asked participants to complete the SCICY a second time after 3 months. As a reward for participation in this study, participants received a credit note of $€ 5$.

\section{Analysis}

First, an exploratory factor analysis on the 30 items was conducted in the full sample. The scree test and principal component analysis (Field, 2009) with direct oblimin rotation and Kaiser normalization were performed. Next, the reliability of the SCICY was evaluated with regard to internal consistency (Cronbach's alpha) and test-retest reliability (Pearson product-moment correlations). A 3-month interval was chosen for the test-retest reliability.

Convergent validity was investigated by inspecting the Pearson product-moment correlation matrix of the SCICY subscales with other measures. Discriminant validity was assessed using an analysis of variance with sexual functioning as the fixed factor and SCICY total as the dependent variable. Two groups were created using a median split based on the Female Sexual Function Index: For low sexual functioning $(n=112), M=16.22, S D=7.28$; for high sexual functioning $(n=117), M=30.44, S D=2.39$. Furthermore, a multivariate analysis of variance was performed, with low versus high sexual functioning as the fixed factor and the SCICY subscales as the dependent variables. A logistic regression analysis using the maximum likelihood method (Hosmer \& Lemeshow, 1989) was also conducted with low versus high sexual functioning as to-be-predicted variable and the SCICY as predictor variable. Sensitivity and specificity are defined as the proportion of subjects with low and high sexual functioning, which has been correctly identified by the regression model of their SCICY scores. Of further importance for the qualifications of the SCICY as a clinical screening instrument are the positive and negative predictive values, which were calculated on the basis of the same logistic regression model. Positive predictive value is defined as the proportion of positive predictions (the subject is predicted by the SCICY scores to report low sexual functioning), which coincide with the observed presence of a sexual problem. Negative predictive value is defined as the proportion of negative predictions (the subject is predicted by the SCICY scores to report high sexual functioning), which coincide with the observed absence of a sexual problem. 


\section{RESULTS}

\section{Questionnaire Development}

A review of the empirical literature was conducted to ascertain domains pertinent to sexual competence and interaction competence. Items were generated in the categories of knowledge, attitude, self-efficacy, and social influence regarding sexual interaction and functioning. The items (99 in total) were compiled in a single questionnaire, which was then administered to 10 male $(M=21.90, S D=2.60)$ and 39 female $(M=21.41, S D=2.22)$ undergraduate students. Besides answering every item, participants gave their opinion about the understandability of each particular item and its suitability for a questionnaire addressing sexuality in adolescents (a score between 0 and 100). On the basis of these answers, the questionnaire was revised.

We excluded 48 items because the participants found them not suitable. Furthermore, we excluded 19 items because participants were not able to understand them correctly. Last, 2 items were excluded because they were found not to differentiate between participants. Excluding these items resulted in a 30-item questionnaire.

\section{Factor Analysis}

We used direct oblimin rotation to conduct a principal component analysis on the 30 items. We used the Kaiser-Meyer-Olkin (KMO) measure to verify the sampling adequacy for the analysis, $\mathrm{KMO}=.855$ (excellent, according to Field, 2009). Not all KMO values for individual items were higher than the acceptability limit of $r=.5$ (Field, 2009). Bartlett's test of sphericity, $\chi^{2}(435)=3046.045, p<.001$, indicated that the interitem correlations were sufficiently large for principal component analysis. An initial analysis was run to obtain eigenvalues for each component in the data. A factor loading of .40 and higher was required to assign items to components. Eight components, including 26 items, had eigenvalues above Kaiser's criterion of 1 , and together explained $61.12 \%$ of the variance. The scree plot was slightly ambiguous and showed inflections that would justify retaining both three and four components. The scree plot (see Figure 1) would suggest retaining three or four components; however, this solution was not optimal considering the content and interpretation of the components. Given the relatively large sample size and the evaluation of Kaiser's criterion, eight components, including 26 items, were retained in the final analysis (see Table 1). The first factor (communication about sex) represents communication behavior that is directed at promoting sexual hedonism and satisfaction for both oneself and the partner. The second factor (refusing sex) refers to attitudes concerning the refusal of sexual activities. The third factor (positive sexual attitudes) contains both the positive feelings experienced after sexual contact as well as respect expressed towards and received from the sexual partner. The fourth factor (male role in sexual interaction) represents the prejudice one can foster about the relationship between being male and aspects of sexuality. The fifth factor (contraceptive use) refers to the communication about using contraceptives to prevent sexually transmitted infections and unwanted pregnancy. The sixth factor (not suppressing problems and desires regarding sex) refers to (the lack of) communication about problems and wishes concerning sex. The seventh factor (sexual assertiveness) represents the ability of the female adolescent to stand up for her own rights and desires, such as in refusing sexual contact. Last, 


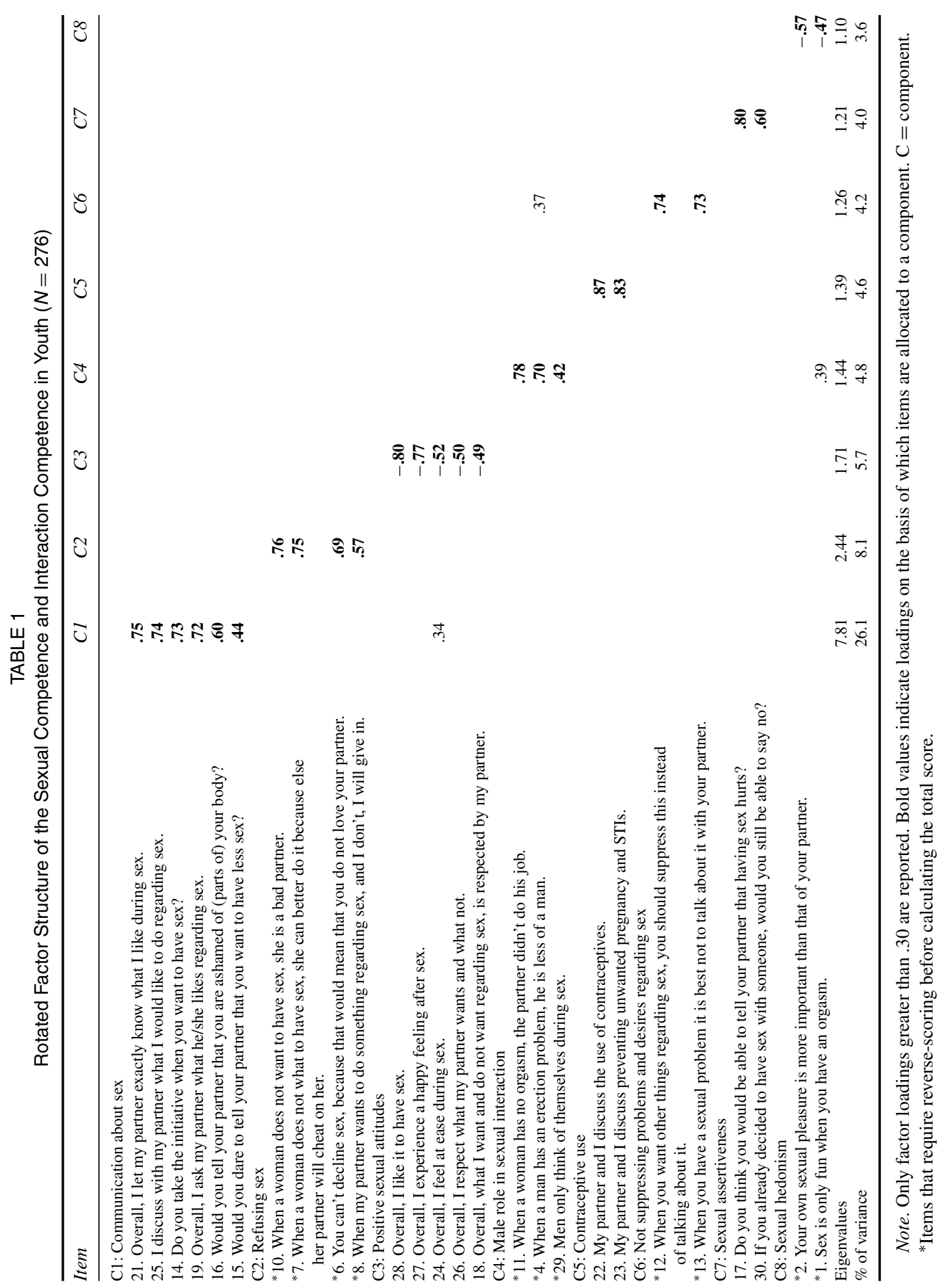




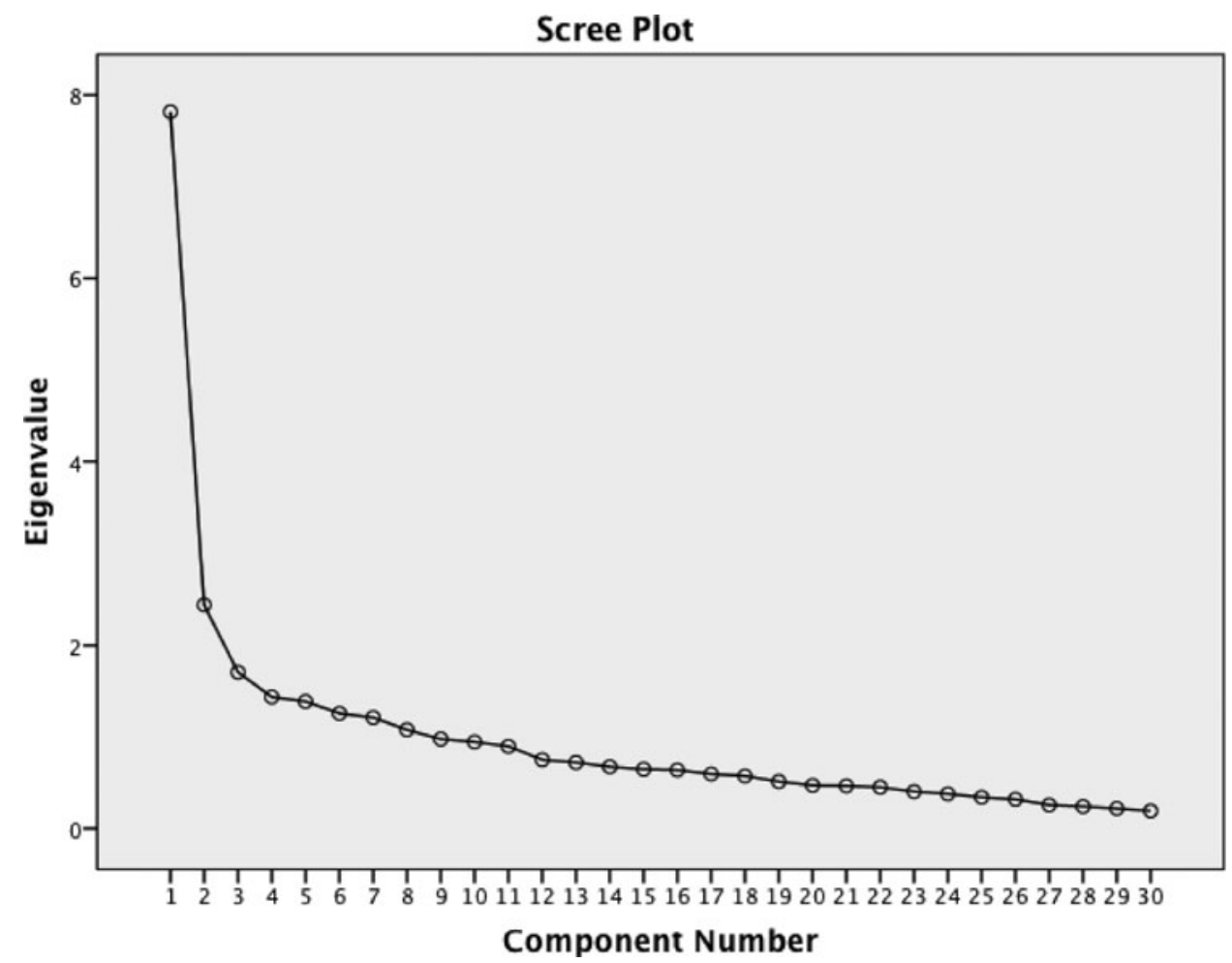

FIGURE 1 Scree plot of initial prinicpal component analysis with 30 SCICY items. SCICY = Sexual Competence and Interaction Competence in Youth.

the eight factor (sexual hedonism) consists of statements that represent the conditions that are required to experience sexual activities as pleasurable.

To further investigate the factor structure of the SCICY, we conducted a second-order principal component analysis on the eight components with eigenvalues above 1 with direct oblimin rotation. The KMO measure was used to verify the sampling adequacy for the analysis, $\mathrm{KMO}=.701$ (good, according to Field, 2009). Bartlett's test of sphericity, $\chi^{2}(28)=164.02$, $p<.001$, indicated that the interitem correlations were sufficiently large for principal component analysis. An initial analysis was run to obtain eigenvalues for each component in the data. A factor loading of .40 and higher was required to assign items to components. Two components, including the eight original components, had eigenvalues above Kaiser's criterion of 1 , and together explained $41.02 \%$ of the variance. The first factor (receiving factors loadings from communication about sex, refusing sex, positive sexual attitudes, contraceptive use, and sexual assertiveness) contains both communication and attitudes about sex. The second factor (receiving factors loadings from male role in sexual interaction, not suppressing problems and desires regarding sex, and sexual hedonism) represents the goal or outcome of sexual encounters. The first factor can be interpreted as corresponding with the interaction competence construct, and the second factor as corresponding more with sexual competence. 


\section{Reliability}

We assessed two aspects of reliability: internal consistency and test-retest. The internal consistency for the SCICY total was good (Cronbach's $\alpha=.88$ ). The internal consistency of the communication about sex and contraceptive use factors was also good $(\alpha=.84$ and .82 , respectively). The refusing sex, positive sexual attitudes, and not suppressing problems and desires regarding sex factors had acceptable internal consistency $(\alpha=.72, .77$, and .70, respectively). Cronbach's alpha for the male role in sexual interaction, sexual assertiveness, and sexual hedonism factors was poor ( $\alpha=.56, .53$, and .49 , respectively).

The test-retest reliability of the SCICY was satisfactory for the total scale $(r=.78, p<.001)$ and moderate to excellent for the subscales (communication about sex: $r=.76, p<.001$; refusing sex: $r=.68, p<.001$; positive sexual attitudes: $r=.54, p<.001$; male role in sexual interaction: $r=.54, p<.001$; contraceptive use: $r=1.00, p<.001$; not suppressing problems and desires regarding sex: $r=1.00, p<.001$; sexual assertiveness: $r=.52, p<.001$; sexual hedonism: $r=$ $.60, p<.001)$.

\section{Validity}

\section{Convergent Validity}

Table 2 shows the correlations of the SCICY with partner communication (PCS) and sexual self-concept (MSSCQ). The total SCICY was significantly and positively related to the PCS ( $r=$ $.31, p<.001)$. The magnitude of the relation between the PCS total and the SCICY subscales varied. There was no significant association between (a) the PCS total and (b) refusing sex and sexual hedonism. Overall, correlations for the PCS total score were the strongest with positive sexual attitudes and the SCICY total.

There were significant and positive correlations between the total SCICY and almost all of the positive MSSCQ subscales (e.g., sexual satisfaction). Furthermore, there were significant and negative correlations between the total SCICY and all of the negative MSSCQ subscales (e.g., sexual depression). Sexual hedonism had the fewest significant correlations with the MSSCQ subscales. Overall, correlations for the MSSCQ subscales were highest with SCICY total, communication about sex, and positive sexual attitudes.

\section{Discriminant Validity}

Analysis of variance and multivariate analysis of variance group comparisons (based on the Female Sexual Function Index) were used to investigate the discriminant validity of the SCICY and its components. Results of the analysis of variance showed that, on average, the SCICY total was higher for the high sexual functioning group $(M=34.72, S D=3.12)$ than for the low sexual functioning group $(M=31.31, S D=4.22 ; F[1,235]=50.08, p<.001)$. Female adolescents with higher levels of sexual functioning scored significantly higher on sexual and interaction competence than those with lower levels of sexual functioning.

Furthermore, multivariate analysis of variance revealed a number of group differences on the SCICY subscales $F(1,235)=12.43, p<.001$. Post hoc tests with Bonferroni corrections were conducted. Scores on all subscales, except sexual hedonism, were significantly different between 


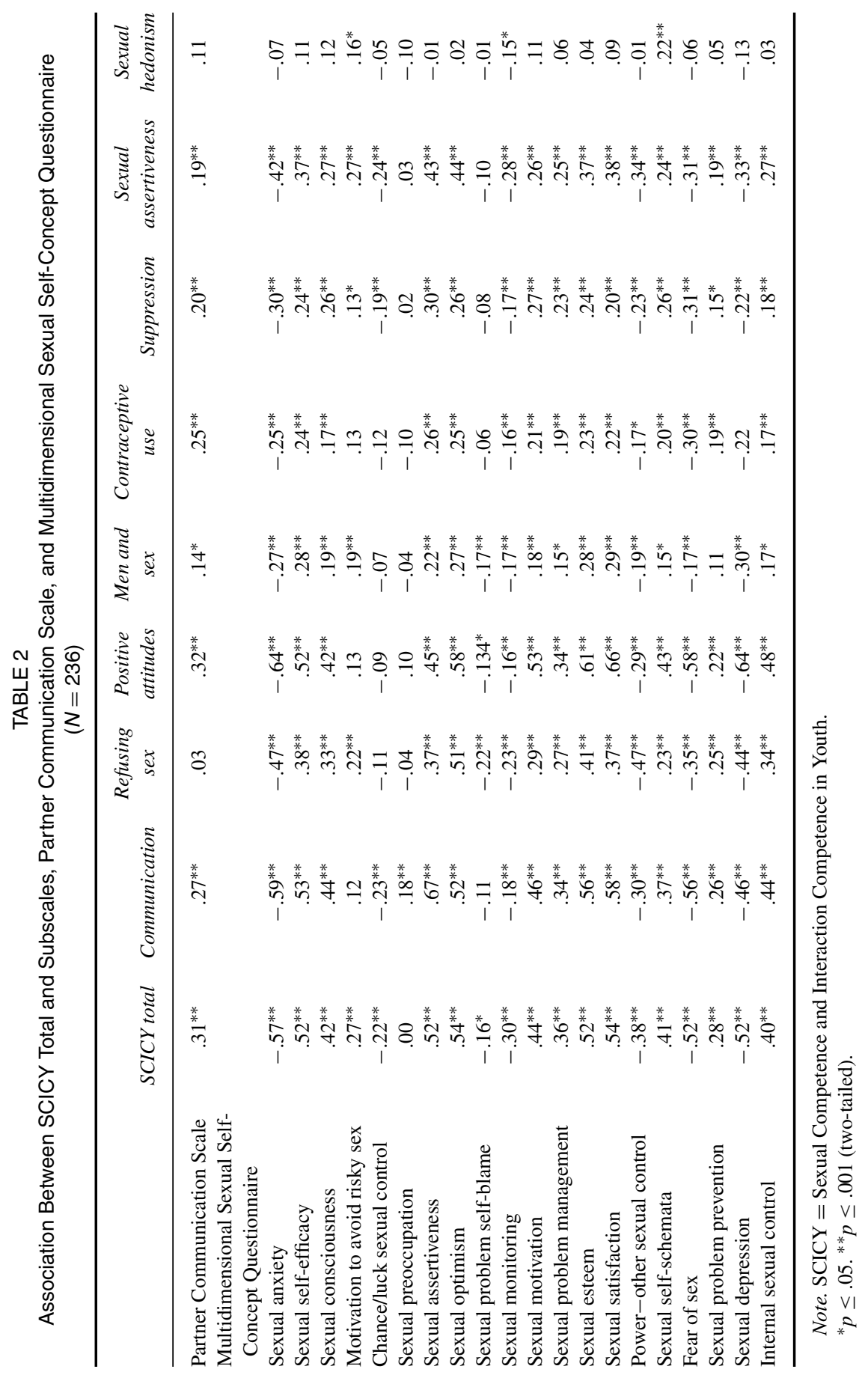


both groups. Subscale scores on the following factors were higher for the high sexual functioning group than for the low sexual functioning group: communication about sex, $t(234)=-6.32, p<$ .001 ; refusing sex, $t(234)=-2.85, p<.05$; positive sexual attitudes, $t(234)=-8.48, p<.001$; male role in sexual interaction, $t(234)=-3.22, p<.05$; contraceptive use, $t(234)=-3.52, p<$ .001 ; not suppressing problems and desires regarding sex, $t(234)=-2.50, p<.05$; and sexual assertiveness, $t(234)=-1.78, p<.001$.

Regression analysis with group membership (low vs. high sexual functioning) as to-bepredicted variable, and the SCICY total score as predictor variable, produced a significant model, $\chi^{2}(1)=54.10, p<.001$, suggesting adequate predictive value of the SCICY total score. The SCICY correctly predicted the overall presence or absence of sexual problems in $71.2 \%$ of the cases. The sensitivity and specificity of this regression model were $66.1 \%$ and $76.1 \%$, respectively, while predictive values positive and negative were $72.5 \%$ and $70.1 \%$, respectively.

\section{DISCUSSION}

The present study aimed to develop and test the psychometric properties of a short self-report questionnaire that can be used to assess sexual competence and interaction competence in adolescents. On the basis of an exploratory factor analysis, the 26-item SCICY was found to represent two higher order factors, containing eight lower-order components. The clustering of items on the lower order components suggests that component 1 represents communication about sex, component 2 represents refusing sex, component 3 represents positive sexual attitudes, component 4 represents male role in sexual interaction, component 5 represents contraceptive use, component 6 represents not suppressing problems and desires regarding sex, component 7 represents sexual assertiveness, and component 8 represents sexual hedonism.

The results of the reliability analysis of the SCICY were mixed. The internal consistencies for the SCICY total and communication about sex and contraceptive use were good, and they were acceptable for refusing sex, positive sexual attitudes, and not suppressing problems and desires regarding sex. The internal consistencies for male role in sexual interaction, sexual assertiveness, and sexual hedonism, however, were unsatisfactory. One explanation for this finding may be the small number of items in each of the subscales ( 3 and 2 items, respectively). The test-rest reliability (with an interval of 3 months between the completion of the first and second questionnaire) of the SCICY total was reasonably good and was moderate to excellent for the subscales.

The convergent validity of the SCICY was assessed against other instruments that intend to measure aspects of sexual competence and interaction competence (PCS and MSSCQ). The associations of the SCICY total with the PCS and subscales of the MSSCQ were of moderate size. The associations were significant except for one subscale of the MSSCQ. This implies that the SCICY appears to measure what it was intended to, namely several aspects of sexual competence (knowledge, preventing risky behavior, psychological aspects) and communication about sex. At the subscale level, communication about sex and positive sexual attitudes had the strongest associations with the other two measures. The correlation of sexual hedonism with the PCS was not significant and this subscale showed the fewest significant associations with the MSSCQ subscales. This low association could be explained by the poor internal consistency of this subscale and the low number of items $(n=2)$. Alternatively, this finding might be due to the fact 
that this element is not represented by the MSSCQ. Adding items to the SCICY that represent the content of the Sexual hedonism subscale may improve the internal consistency of this subscale as well as the convergence with the other instruments. Furthermore, the association between communication about sex and the PCS, although significant, had an unexpected low effect size. A reason for this finding may be the fact that many items of the PCS were not represented in a parallel form in the communication about sex SCICY subscale. Two items of the PCS, concerning the use of contraceptives, form a separate subscale (contraceptive use) in the SCICY. These two items do correlate significantly with the PCS. Another reason is that communication about sex goes beyond communication about contraceptive use, and it also includes expressing one's likes and dislikes regarding sex.

Last, the discriminant validity of the SCICY was investigated. It is thought that low sexual competence and interaction competence of adolescents is associated with sexual risk behavior and sexual function problems. If the SCICY is sensitive enough to differentiate between high and low sexual functioning adolescents, this instrument could be used to prevent or early intervene in these problems. The results show that the SCICY total and all subscales, except sexual hedonism, were significantly higher in high sexually functioning adolescents than in low sexually functioning adolescents. However, because of the low internal consistencies of the male role in sexual interaction and sexual assertiveness subscales, the differences on these subscales must be interpreted with caution. With respect to the sensitivity/specificity analysis, results were not very conclusive. These results indicate that is necessary to replicate this finding in patient populations.

Although designed for both male and female adolescents, this study only collected data of female adolescent students between the age of 18 and 25 years $(M=20$ years). This group was chosen because the prevalence of sexual dysfunctions is the highest in females. It is not certain how the SCICY will generalize to male, younger, and more diverse populations. It is possible that the factor structure and the scores on the subscales differ between these groups. Furthermore, the low internal consistencies of some of the subscales are problematic. The inclusion of more items in this subscale might be a solution here.

Notwithstanding the limitations noted, the present study gives an indication that the SCICY could be used to measure the combination of sexual competence and interaction competence in adolescent females. Furthermore, the limited number of items $(n=26)$ makes this instrument suitable to use in research as well as in clinical practice. The SCICY may have particular utility in sexual health education interventions. Because of its ability to differentiate between high and low sexually functioning adolescents, a lower score on the SCICY might indicate current or future sexual problems. Especially when this is observed in younger adolescents, they might be targeted to prevent the development of sexual function problems. Furthermore, given the known relationship between communication with a sexual partner and consistent condom use (Bakker \& Vanwesenbeeck, 2006; Crosby et al., 2002; DiClemente, 1991; Widman et al., 2006) many health education programs could incorporate this construct. The SCICY can be used to assess the frequency of communicating about the use of contraceptives, both before and after intervention, to prevent sexually transmitted infections and unwanted pregnancy, as well as to evaluate the efficacy of an intervention. Future research with the SCICY should include more diverse samples in terms of gender, age, and sexual orientation to corroborate and extend its applicability. To address its robustness, a confirmatory factor analysis of the SCICY has to be performed. Furthermore, the discriminant validity has to be confirmed by using clinically diagnosed adolescents with sexual dysfunctions. Last, norm scores have to be developed for men and women. 


\section{REFERENCES}

Bakker, F., \& Vanwesenbeeck, I. (2006). Seksuele gezondheid in Nederland 2006 [Sexual health in the Netherlands 2006]. Delft, The Netherlands: Eburon.

Collins, W., Welsh, D., \& Furman, W. (2009). Adolescent romantic relationships. Annual Review of Psychology, 60, 631-652.

Crosby, R., DiClemente, R., Wingood, G., Cobb, B., Harrington, K., Davies, S., .. Kim Oh, M. (2002). Condom use and correlates of African American adolescent females' infrequent communication with sex partners about preventing sexually transmitted diseases and pregnancy Health Education \& Behavior, 29, 219-231.

de Graaf, H., Kruijer, H., van Acker, J., \& Meijer, S. (2012). Seks onder je 25e [Sex under the age of 25]. Utrecht, the Netherlands: Rutgers WPF.

de Graaf, H., Meijer, S., Vanwesenbeeck, I., \& Poelman, J. (2005). Seks onder je 25e. Seksuele gezondheid van jongeren in Nederland anno 2005 [Sex under the age of 25. Sexual health of adolescents in the Netherlands in 2005]. Delft, The Netherlands: Eburon.

DiClemente, R. (1991). Predictors of HIV-preventive sexual behavior in a high-risk adolescent population: The influence of perceived peer norms and sexual communication on incarcerated adolescents' consistent use of condoms. Journal of Adolescent Health, 12, 385-390.

Ferroni, P., \& Taffe, J. (1997). Women's emotional well-being: The importance of communicating sexual needs. Sexual and Relationship Therapy, 12, 127-138.

Field, A. (2009). Discovering statistics using SPSS. New York, NY: Sage.

Guttmacher Institute. (2010). U.S. teenage pregnancies, births and abortions: National and state trends and trends by race and ethnicity.

Guttmacher Institute. (2012). Facts on American teens' sexual and reproductive health.

Hamilton, B., Martin, J., \& Ventura, S. (2010). Births: Preliminary data for 2009. National Vital Statistics Reports.

Hirst, J. (2008). Developing sexual competence? Exploring strategies for the provision of effective sexualities and relationships education. Sex Education, 8, 399-413.

Hosmer, D., \& Lemeshow, S. (1989). Applied logistic regression. New York, NY: Wiley.

Kedde, H. (2012). Seksuele disfuncties in Nederland: Prevalentie en samenhangende factoren [Sexual dysfunctions in the Netherlands: Prevalence and contributing factors]. Tijdschrift voor Seksuologie, 36, 98-108.

Milhausen, R., McDermott Sales, J., Wingood, G., DiClemente, R., Salazar, L., \& Crosby, R. (2007). Valdiation of a partner sexual communication scale for use in HIV/AIDS prevention interventions. Journal of HIV/AIDS Prevention in Children \& Youth, 8, 11-33.

Pazol, K., Zane, S., Parker, W., Hall, L., Gamble, S., Hamdan, S., .. Cook, D. (2011). Abortion surveillance: United States, 2007. Atlanta, GA: National Center for Chronic Disease Prevention and Health Promotion, Centers for Disease Control and Prevention.

Rosen, R., Brown, C., Heiman, J., Leiblum, S., Meston, C., Shabsigh, R., ... D’Agostino, R. Jr. (2000). The Female Sexual Function Index (FSFI): A multidimenstional self-report instrument for the assessment of female sexual function. Journal of Sex \& Marital Therapy, 26, 191-208.

Snell, W. (1995). The Multidimensional Sexual Self-Concept Questionnaire. Retrieved from http://www4.semo.edu/snell/ scales/MSSCQ.HTM

ter Kuile, M., Brauer, M., \& Laan, E. (2006). The Female Sexual Function Index (FSFI) and the Female Sexual Distress Scale (FSFD): Psychometric properties within a Dutch population. Journal of Sex \& Marital Therapy, 32, 289-304.

Wellings, K., Nanchahal, K., Macdowall, W., McManus, S., Erens, B., Mercer, C., . . Field, J. (2001). Sexual behaviour in Britain: early heterosexual experience. The Lancet, 358, 1843-1850.

Widman, L., Welsh, D., McNulty, J., \& Little, K. (2006). Sexual communication and contraceptive use in adolescent dating couples. Journal of Adolescent Health, 39, 893-899.

World Health Organization. (2002). Defining sexual health. Report of a technical consultation on sexual health. Geneva, Switzerland: Author.

World Health Organization. (2011). The sexual and reproductive health of young adolescents. Geneva, Switzerland: Author.

Zimmerman-Gernbeck, M., Siebenbruner, J., \& Collins, W. (2004). A prospective study of intraindividual and peer influences on adolescents' heterosexual romantic and sexual behavior. Archives of Sexual Behavior, 33, 381-394. 